\title{
Correction to: Evaluation of relationships between GSCM practices and SCP using SEM approach: an empirical investigation on Iranian automobile industry
}

\author{
Armin Aalirezaei ${ }^{1}$ (D) Niloofar Esfandi ${ }^{2} \cdot$ Alireza Noorbakhsh $^{3}$ \\ Published online: 11 August 2018 \\ (C) Springer Nature B.V. 2018, corrected publication August/2018
}

\section{Correction to: Jnl Remanufactur (2018) 8(1-2):51-80 \\ https://doi.org/10.1007/s13243-018-0045-y}

The original PDF version of this article unfortunately contains error introduced during the production process. The Publisher apologizes for this error.

The fifth paragraph under "Conclusions and suggestions" section was not properly formatted. The correct paragraph is now given below.

The results of the implementation of this model have showed that the product recycling among four GSCM practices is in the first priority. Moreover, the product disassembly manual has the greatest importance among all 22 GSCM practices indictors. To avoid the misinterpretation dimension of the product recycling as its' criterion, the product disassembly manual, the product recycling initiatives is related to the disposal stage, while the product disassembly manual refers to the consumers education about the recycling and recovery options available to them, and explaining that they must not dispose the products together with their general trash. To facilitate an end-of-life disassembly, the product disassembly manuals need to be carried out as a reference for disassembly workers to implement the non-destructive detachment of components or modules and acquire the recovery of original functionality in order to contribute to the environmental benefit $[6,46]$. In order for Saipa Company and similarly for Iranian automobile companies, to improve GSCM practices by considering the product disassembly manual as the most influential indicator from experts' point of view, it is recommended to set

The online version of the original article can be found at https://doi.org/10.1007/s13243-018-0045-y

Armin Aalirezaei

a.aalirezaei@semnan.ac.ir

1 Department of Industrial Engineering, Semnan University, Semnan, Iran

2 Management Department, University of Tehran, Tehran, Iran

3 Department of Industrial and Information Engineering, Politecnico di Milano, Milan, Italy 
up a management system for their products disassembly manual which provides the required instructions on how to take care of items containing the environmental hazardous materials. Furthermore, based on the viewpoint of the product lifecycle management practice, it is beneficial to make a database including the information of the products for instance their end of life for making such database is scored as the most significant factor in LCM practice. As another practical solution to improve GSCM practices, concerning the suppliers management, Saipa is suggested to design the suppliers environmental questionnaires as an extended producer responsibility and distribute to suppliers for helping them conduct a self-assessment and for ensuring the suppliers to realize their environmentally potential capabilities which satisfy the environmental regulations particularly for high-risk components. All those aforementioned suggestions would result in the enhancement of GSCM practices by which SCP in Saipa would be improved as well. 